\title{
Morfologia do fruto, das sementes e dos estádios iniciais de desenvolvimento de Helicostylis tomentosa
}

\author{
Yêda Maria Boaventura Corrêa Arruda ${ }^{1 *}$, Isolde Dorothea Kossmann Ferraz ${ }^{2}$, Angela Maria da Silva Mendes ${ }^{1}$ \\ ${ }^{1}$ Universidade Federal do Amazonas, Av. Rodrigo Otavio Jordão Ramos, 6200, Setor Sul, Coroado, CEP 69080-900, Manaus, AM, Brasil \\ ${ }^{2}$ Instituto Nacional de Pesquisas da Amazônia, Av. André Araújo, CP. 6905506, Petrópolis, CEP 69067-375, Manaus, AM, Brasil
}

^Autor correspondente:
yedaarruda@gmail.com

Termos para indexação:

Plântulas

Germinação

Desenvolvimento da planta

Index terms:

Seedlings

Germination

Plant development

Histórico do artigo:

Recebido em 25/04/2017

Aprovado em 30/11/2017

Publicado em 29/12/2017

doi: 10.4336/2017.pfb.37.92.1439
Resumo - Os objetivos deste estudo foram analisar as características morfológicas complexas dos frutos e diásporos de inharé, e fornecer subsídios para o reconhecimento da planta na fase inicial do desenvolvimento. As infrutescências apresentam, em média, 2,2 cm x 2,9 cm x 2,6 cm, com 4-10 frutos inseridos ao perianto carnoso. Os frutos, drupas monospérmicas, apresentam um pericarpo fino-gelatinoso, que contem um pirênio globoso, levemente achatado, marrom opaco e liso medindo $0,9 \mathrm{~cm} \times 0,8 \mathrm{~cm}$ $\mathrm{x} 0,6 \mathrm{~cm}$. A semente exalbuminosa possui tegumento membranoso; o embrião é axial total e as reservas encontram-se nos cotilédones crassos e isófilos. A germinação é tipo hipógea criptocotiledonar; com a retirada do endocarpo, a protrusão da raiz primária ocorre após 10 dias da semeadura e a plântula normal aos 30 dias está completamente formada. A plântula possui os primeiros eofilos com filotaxia alterno-espriralada, forma elíptica com base atenuada, ápice agudo a acuminado e margem denteada; o epicótilo é cilíndrico, com aproximadamente $1,0 \mathrm{~cm}$ de comprimento, e possui catafilos; o sistema radicular é bem desenvolvido, com muitas raízes secundárias. As plantas jovens, entre $50 \mathrm{~cm}$ a $115 \mathrm{~cm}$ de altura, apresentam similaridades morfológicas com o indivíduo adulto, principalmente no tocante ao caule e às folhas.

\section{Morphology of fruit, seeds and initial stages of Helicostylis tomentosa}

\begin{abstract}
The objectives of this study were to analyze the complex morphological characteristics of fruits and diaspores of inharé, and provide support for the recognition of the plant in the early stage of development. The inflorescences have on average $2.2 \mathrm{~cm} \times 2.9 \mathrm{~cm} \times 2.6 \mathrm{~cm}$, with $4-10$ fruits entered the fleshy perianth. The fruits, monospermics drupes, have a fine-gelatinous pericarp. The endocarp form the pyrene, globular, slightly flattened, brown opaque, smooth and hardened, measuring $0.9 \mathrm{~cm} \mathrm{x}$ $0.8 \mathrm{~cm} \times 0.6 \mathrm{~cm}$. The seed has exalbuminous membranous integument; the embryo is full axial and reserves are in crass and isofils cotyledons. Germination is kind hypogeal cryptocotylar; with the removal of the core the primary root protrusion occurs after 10 days of sowing and the normal seedlings at 30 days is completely formed. The seedling has the first eophylls with alternates spirals phyllotaxis, elliptical shape with base attenuate, apex acute to acuminate and jagged edges; epicotyl is cylindrical, about $1.0 \mathrm{~cm}$ long, has cataphylls; the root system is well developed, with many secondary roots. Young plants, between $50 \mathrm{~cm}$ and $115 \mathrm{~cm}$ in height, show morphological similarities to adult individual mainly in leaves and stems.
\end{abstract}




\section{Introdução}

A família Moraceae é predominantemente tropical e abundante na Ásia e Austrália. Apresenta aproximadamente 50 gêneros e 1.500 espécies (Souza \& Lorenzi, 2005). Helicostylis, gênero com sete espécies (Pennington et al., 2004), possui ampla distribuição na região tropical. No Neotrópico ocorrem todas as espécies: H. elegans, $H$. heterotricha; $H$. pedunculata, $H$. scabra, $H$. tomentosa, $H$. tovarensis e $H$. turbinata, e na bacia Amazônica somente duas não foram encontradas (H. pedunculata e H. tovarensis) (Berg, 2001). Nas proximidades de Manaus, AM, foram registradas em floresta de terra firme $H$. tomentosa, $H$. scabra e $H$. turbinata (Ribeiro et al., 1999). H. tomentosa está entre as 20 espécies mais abundantes (hiperdominantes) da flora arbórea da Amazônia (Steege et al., 2013). A importância da família no Brasil é remetida ao valor econômico das espécies madeireiras (Ribeiro et al., 1999).

Helicostylis tomentosa (Poep. \& Endl.) Rusby é uma espécie de hábito arbóreo, com mais de $30 \mathrm{~m}$ de altura, perenifolia da floresta primária; apresenta ampla distribuição desde o norte da América do Sul até o leste dos Andes (Berg, 2001). No Brasil, é popularmente chamada de inharé, inharé-paina e inharé-folha-peluda, e apresenta domínio fitogeográfico na Amazônia e Mata Atlântica, podendo ocorrer em Campinarana, Floresta Ciliar ou Galeria, Floresta de Terra Firme e Floresta Pluvial (Flora do Brasil, 2016). Sua madeira é indicada para construção pesada e confecção de móveis (Steege et al., 1996).

Os gêneros da família Moraceae apresentam uma variação no que se refere às características morfológicas germinativas. Têm sementes sem e com endosperma (Hong et al., 1998), com cotilédones de reserva (por exemplo, Myrianthus e Treculia) ou foliáceos (por exemplo, Musanga, Morus e Chlorophora) (Mensbruge, 1966). Possuem representantes com embrião curvo ou reto (Corner, 1976; Hong et al., 1998), pequeno ou grande (Corner, 1976), com germinação epígea (por exemplo, Chlorophora, Morus, Myrianthus, Musanga e Treculia) ou hipógea (por exemplo, Antiaris e Bosquiea) (Hong et al., 1998).

As referências encontradas sobre a espécie em estudo se detêm à descrição botânica e às propriedades físicas da madeira. Apesar de ser uma espécie madeireira com abundante produção de sementes e boa regeneração natural, são incompletas as informações quanto à morfologia dos frutos e das sementes e inexistentes sobre o crescimento e o desenvolvimento da plântula e das fases subsequentes. $\mathrm{O}$ comportamento germinativo da semente e o desenvolvimento inicial da planta são estágios críticos para o seu estabelecimento e, portanto, pesquisas sobre estes aspectos são relevantes para o conhecimento da espécie (Gogosz et al., 2010).

O estudo morfológico das plântulas, em sua primeira fase de desenvolvimento, antes da produção das folhas definitivas, permite a descoberta de estruturas transitórias primitivas ou derivadas que desaparecem com o desenvolvimento da planta, mas que podem ter extraordinária importância para se estabelecerem relações de parentesco ou conexões filogenéticas com grupos, cujos órgãos adultos apresentem essas características (Paoli \& Bianconi, 2008).

Assim, o conhecimento da morfologia da plântula e da fase juvenil permite a identificação da regeneração natural e pode subsidiar estudos sobre a dinâmica populacional e o manejo da espécie.

O objetivo deste trabalho foi caracterizar a morfologia externa da infrutescência, da semente, do processo germinativo, da plântula e da planta jovem de $H$. tomentosa.

\section{Material e métodos}

Os ramos reprodutivos foram coletados de matrizes identificadas da Reserva Florestal Adolfo Ducke $\left(03^{\circ} 08^{\prime} \mathrm{S}\right.$ e $\left.59^{\circ} 52^{\prime} \mathrm{W}\right)$, com registro 237.810 e 54.767 no herbário do Instituto Nacional de Pesquisas da Amazônia (INPA). As infrutescências foram transportadas em saco plástico para o laboratório. O tempo estimado entre a coleta e o beneficiamento das sementes não excedeu $24 \mathrm{~h}$.

O estudo da morfologia e da morfometria foi baseado em 30 infrutescências e 30 pirênios. As dimensões (comprimento, largura e espessura), foram tomadas com auxílio de um paquímetro digital $(\mathrm{cm})$ e o peso da matéria fresca e seca em balança analítica com precisão de $0,001 \mathrm{~g}$. O teor de água, expresso em porcentagem da matéria fresca, foi determinado com 25 pirênios, pesados individualmente antes e após secos até atingirem peso constante, em estufa de $75^{\circ} \mathrm{C}$ com ventilação forçada. A terminologia empregada, para a descrição dos caracteres morfológicos dos frutos e diásporos foi baseada em Martin (1946), Roth (1977), Barroso et al. (1999), FontQuer (2001) e Camargo et al. (2008). 
O estudo morfológico das plântulas, bem como a descrição do processo germinativo, foi realizado com 20 indivíduos com observações in natura. Para as descrições, também foi utilizado material herborizado e conservado (álcool 70\% glicerinado) das mesmas fases. As plântulas foram obtidas a partir da germinação das sementes em germinador, sob temperatura de $30{ }^{\circ} \mathrm{C}$ $\left( \pm 2{ }^{\circ} \mathrm{C}\right.$ ), identificada como ótima para a espécie (Ferraz et al., 1998). O substrato utilizado foi vermiculita expandida, tamanho médio e os recipientes foram caixas plástica transparente, tipo gerbox $(11 \times 11 \times 3$ $\mathrm{cm})$, envolvidas em saco plástico fino e transparente ( \pm $0,003 \mathrm{~mm}$ ) para evitar a perda excessiva de umidade. No teste de germinação, foram utilizadas quatro repetições de 25 sementes, semeadas sob o substrato para facilitar a visualização.

O tratamento pré-germinativo constou da retirada do endocarpo. Para tal, os propágulos foram dessecados por cerca de $14 \mathrm{~h}$ em ambiente com ar-condicionado $\left(\mathrm{T}_{\text {média }}=26,4^{\circ} \mathrm{C}\right.$; U.R. $\left.{ }_{\text {média }}=73 \%\right)$ e a seguir retirado manualmente o envoltório com auxílio de uma faca. $\mathrm{O}$ processo germinativo foi observado diariamente desde a semeadura até a formação dos primeiros eofilos. Durante este período, foram descritos os aspectos morfológicos do desenvolvimento da raiz, do hipocótilo e do epicótilo, o tipo e a morfologia dos cotilédones e dos eofilos. Foi considerada plântula o estádio quando houve a formação dos primeiros eofilos e planta jovem as diversas fases do juvenil, desde que apresentassem características morfológicas diferentes das folhas do indivíduo adulto (Camargo et al., 2008). Os aspectos morfológicos da planta jovem foram descritos e comparados em três classes de altura: 5,0 a 10,0 cm, 20,0 a 25,0 cm e 50,0 a $115,0 \mathrm{~cm}$. A terminologia empregada, para a descrição dos caracteres morfológicos e do processo germinativo, foi baseada em Ribeiro et al. (1999), Hickey \& King (2000) e Font-Quer (2001).

\section{Resultados}

\section{Morfometria das infrutescências, frutos e pirênios}

Observaram-se os frutos inseridos (adnatos) parcialmente no receptáculo e eixo da inflorescência, que formam a parte carnosa da infrutescência (Figura 1-A). As infrutescências, quando maduras, apresentaram coloração amarela, com consistência carnosa e textura aveludada, recobertas por pelos; com 4 a 10 frutos.
Observou-se o perianto de quatro lóbulos (Figura 1a), amarelo e carnoso, envolvendo o fruto durante a maturação e deixando uma fenda pela qual o estilete ultrapassa e permite que o estigma permaneça visível (Figura 1a). Na infrutescência madura, o fruto pode ser facilmente extraído devido à suculência e maciez do perianto e do receptáculo. Na extração do fruto ocorre normalmente a perda do estigma persistente (Figura 1b). Cada fruto, de forma elipsoide, é uma drupa monospérmica, cujo epicarpo e/ou mesocarpo é um tecido gelatinoso, translúcido e fino. Após a extração, notou-se que o tecido gelatinoso resseca e forma uma película de cor branca, cobrindo o endocarpo marrom escuro.
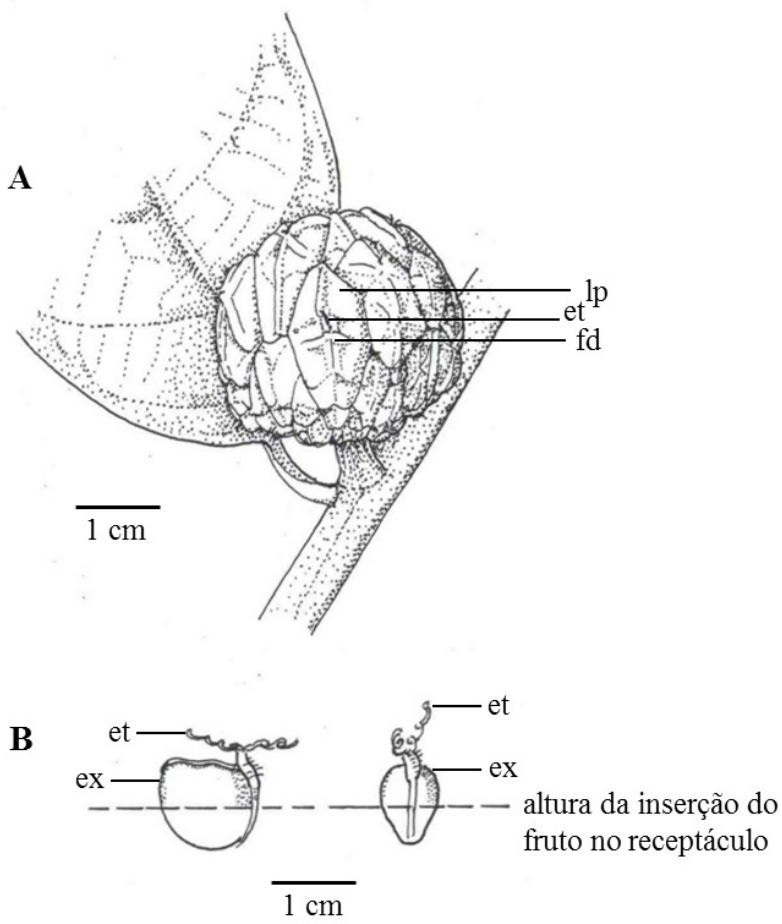

Figura 1. Morfologia externa da infrutescência e do fruto de Helicostylis tomentosa (Poep. \& Endl.) Rusby. A - Infrutescência. B - Fruto. et - estigma; fd - fenda; ex exocarpo; lp - lóbulo do perianto.

A infrutescência apresentou forma subglobosa a globosa, com média de 2,2 $\mathrm{cm}$ de comprimento, 2,9 $\mathrm{cm}$ de largura, 2,6 $\mathrm{cm}$ de espessura e 11,9 $\mathrm{g}$ de peso da matéria fresca (Tabela 1).

$\mathrm{O}$ endocarpo foi observado aderido à semente, formando um pirênio globoso, quase elipsoide e levemente achatado (Figura 2a) com $0,9 \mathrm{~cm}$ de 
comprimento, $0,8 \mathrm{~cm}$ de largura, $0,6 \mathrm{~cm}$ de espessura e $0,25 \mathrm{~g}$ de peso da matéria fresca (Tabela 1). Apresentava superfície lisa, com consistência lenhosa (Figuras 2a e 2c), porém cartácea quando seco, de coloração marrom escura e opaca (Figura 2b); a rafe se apresentava na região ventral, tornando a porção apical levemente truncada; o funículo persistente pode ser observado na região ventral logo abaixo da rafe (Figura $2 \mathrm{a}$ e $2 \mathrm{c}$ ).

Tabela 1. Biometria das infrutescências e dos pirênios, recém-coletados $(\mathrm{n}=30)$, de Helicostylis tomentosa (Poep. \& Endl.) Rusby.

\begin{tabular}{|c|c|c|c|}
\hline & Média \pm dp & Mínimo & Máximo \\
\hline \multicolumn{4}{|c|}{ Infrutescência } \\
\hline Comprimento $(\mathrm{cm})$ & $2,21 \pm 0,24$ & 1,91 & 2,92 \\
\hline Largura (cm) & $2,98 \pm 0,35$ & 2,43 & 3,77 \\
\hline Espessura (cm) & $2,59 \pm 0,25$ & 2,24 & 3,08 \\
\hline $\begin{array}{l}\text { Peso da matéria } \\
\text { fresca }(\mathrm{g})\end{array}$ & $11,9 \pm 2,9$ & 6,7 & 19,4 \\
\hline \multicolumn{4}{|c|}{ Pirênio } \\
\hline Comprimento $(\mathrm{cm})$ & $0,90 \pm 0,06$ & 0,71 & 0,98 \\
\hline Largura $(\mathrm{cm})$ & $0,81 \pm 0,07$ & 0,63 & 0,91 \\
\hline Espessura (cm) & $0,55 \pm 0,04$ & 0,46 & 0,67 \\
\hline $\begin{array}{l}\text { Peso da matéria } \\
\text { fresca }(\mathrm{g})\end{array}$ & $0,25 \pm 0,05$ & 0,15 & 0,36 \\
\hline $\begin{array}{l}\text { Peso da matéria } \\
\text { seca }(\mathrm{g})\end{array}$ & $0,15 \pm 0,03$ & 0,09 & 0,22 \\
\hline Teor de água (\%) & $39,26 \pm 2,52$ & 35,48 & 45,58 \\
\hline
\end{tabular}

$\mathrm{dp}=$ desvio padrão da amostra

A semente se encontrava adnato ao endocarpo, com tegumento delgado, membranoso, de coloração marrom e brilhante (Figura 2b). Nas sementes maduras não foi observado endosperma, portanto são classificadas como exalbuminosas. O embrião era axial total, apresentando consistência carnosa endurecida (Figura 2b); os cotilédones eram crassos, isófilos, oblongos e justapostos pela face abaxial, fendido com a radícula exposta (Figuras $2 \mathrm{~b}$ e $2 \mathrm{~d}$ ), de coloração amarelo-clara e opaca; o eixo embrionário é elipsoide, subapical, localizado na região mais larga dos cotilédones (Figura 2d), com plúmula indiferenciada; a parte do eixo embrionário abaixo do nó cotiledonar (correspondente ao hipocótilo e à radícula) apresentou comprimento médio de $0,15 \mathrm{~cm}$ $(0,14-0,16 \mathrm{~cm})$ e largura média de $0,13 \mathrm{~cm}(0,12-0,14$ $\mathrm{cm}$ ) (Figura 2d).
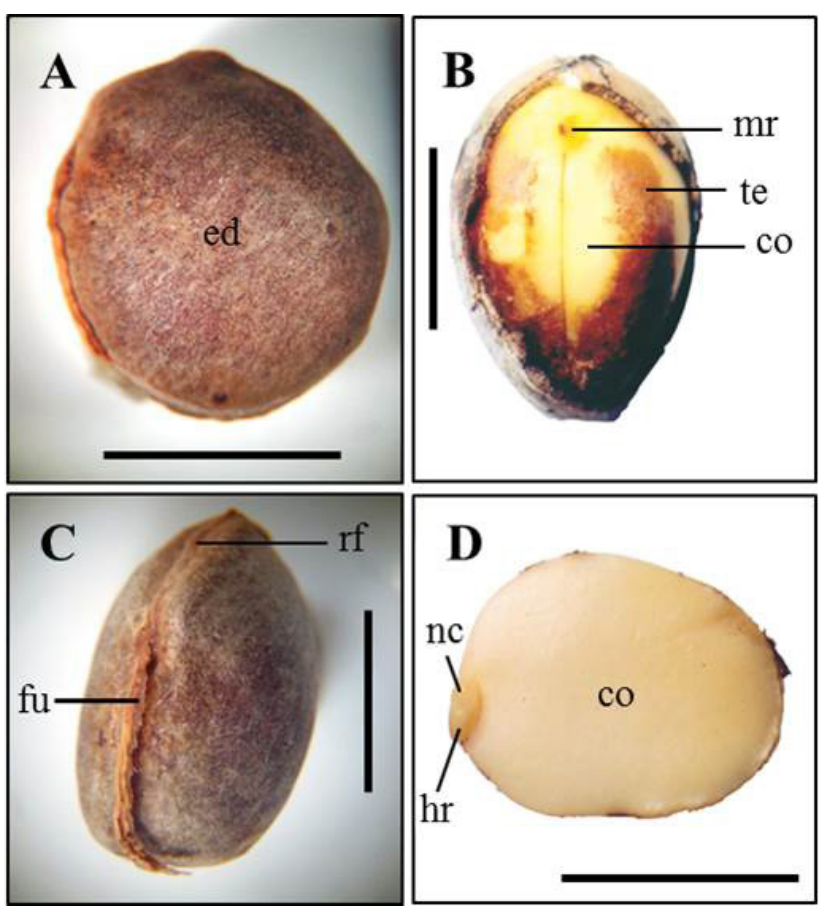

Figura 2. Morfologia externa e interna do pirênio de Helicostylis tomentosa (Poep. \& Endl.) Rusby. A - Aspecto geral do pirênio. B - Pirênio com endocarpo parcialmente removido, expondo a semente (tegumento e o embrião). C Detalhe da região ventral do pirênio, evidenciando a rafe e o funículo persistente. D - Detalhe do embrião com visualização do eixo embrionário. co - cotilédone; ed - endocarpo; $\mathrm{hr}$ - eixo hipocótilo-radícula; fu - funículo; rf - rafe; $\mathrm{mr}$ - meristema radicular; nc - nó cotiledonar; te - tegumento. Barra 5,0 mm. Fotos: A e C - Angela Maria da Silva Mendes. B e D - Isolde Dorothea Kossmann Ferraz.

\section{Descrição do processo germinativo}

O processo germinativo das sementes iniciou visualmente com o intumescimento do eixo embrionário (Figura 3a). Sob condições ótimas de temperatura $\left(30^{\circ} \mathrm{C}\right)$ e após retirada do endocarpo, a protrusão da raiz primária branca e delgada ocorreu em, aproximadamente, 10 dias após a semeadura (DAS) (Figura 3b). Foi observado que antes do desenvolvimento do epicótilo, que ocorreu aos 20 DAS, houve o desenvolvimento abundante de raízes secundárias, também delgadas (Figura 3c). O eixo (epicótilo) se alongou retilíneo e apresentou dois a cinco catafilos (Figura 3d), antes da formação dos primeiros 
eofilos aos 30 DAS, aproximadamente (Figura 3e). Os cotilédones permaneceram ao nível do solo, pois em nenhum momento ocorreu o alongamento do hipocótilo. Assim a germinação pode ser classificada como hipógea e criptocotiledonar com cotilédones persistentes na fase plantular, sem sinal de exaustão (Figura 3e). Em condições naturais, foi observado que os cotilédones permanecem envoltos pelo endocarpo durante todo o processo germinativo.

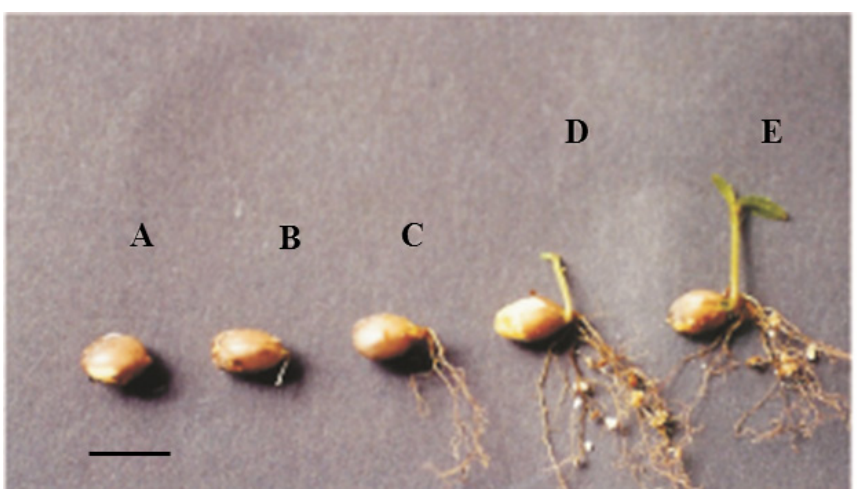

Figura 3. Processo germinativo de Helicostylis tomentosa (Poep. \& Endl.) Rusby. A - Intumescimento do eixo embrionário. $\mathrm{B}$ - Protrusão da raiz primária. C Desenvolvimento das raízes secundárias. D - Alongamento do epicótilo com presença de catafilos. E - Expansão do primeiro par de eofilos, plântula normal. Barra $=1,0 \mathrm{~cm}$. Foto: Isolde Dorothea Kossmann Ferraz.

\section{Morfologia da plântula e morfologia comparativa da planta jovem}

A plântula normal apresentava sistema radicular axial ou pivotante, com raízes secundárias e terciárias bem desenvolvidas (Figura 4b), de coloração marrom, e o hipocótilo minúsculo, também de coloração marrom, intumescente (Figura 4a). Os cotilédones estavam posicionados lateralmente ao eixo (Figura 4a), podendo eventualmente apresentar bordas verdes após a retirada do endocarpo para facilitar a germinação. Foi observado epicótilo (Figura 4b) cilíndrico, com diâmetro basal médio de $0,08 \mathrm{~cm}(0,05-0,11 \mathrm{~cm})$, atingindo altura média de $0,9 \mathrm{~cm}(0,4-2,0 \mathrm{~cm})$, com coloração variando de marrom-escuro na região basal a verde na região apical; e com superfície pilosa tendo pelos simples ao longo do epicótilo, em disposição alterna espiralada. Foi observada a presença de dois a cinco catafilos pequenos (Figura 4a e 4b), às vezes o último catafilo se desenvolveu um pouco mais. O eofilo era uma folha simples, curto-peciolada com filotaxia sub-oposta ou alterna e prefolheação conduplicada (Figura 4b); o limbo foliar era ovado ou simétrico-lanceolado, com base e ápice arredondados e margem inteira e, às vezes, levemente serreada, com venação peninérvea; em toda lâmina foliar e nas nervuras ocorriam tricomas simples e curtos, que conferiam uma textura áspera, com sua coloração variando de verde-clara a verde-escura.

As plantas jovens entre $5,0 \mathrm{~cm}$ a $10,0 \mathrm{~cm}$ de altura (Figura 4c) apresentaram raízes secundárias bem desenvolvidas, mesmo quando semeadas em areia. Os cotilédones continuaram persistentes. O caule cilíndrico sublenhoso, com coloração marrom-clara, era piloso por toda sua extensão, os pelos longos e curvados formavam um tapete e conferiam uma superfície tomentosa; os catafilos continuaram presentes. As folhas apresentavam filotaxia alterno-espiralada; possuindo prefolheação conduplicada; as estípulas intrapeciolares eram triangulares com ápices atenuados e pilosos; o pecíolo era curto e piloso; a forma do limbo, elíptica, raramente obovada, com base atenuada, raramente arredondada, e ápice agudo a acuminado, raramente arredondado; a margem comumente denteada nas folhas jovens e serreada nas folhas maduras; foi observada venação pinada quase plana na face adaxial e proeminente na face abaxial, com visualização das nervuras quaternárias; a nervura central possuia pelos mais longos e embaraçados na face adaxial, curtos e eretos na face abaxial; a venação secundária era broquidódroma, a face adaxial era plana e glabra, enquanto a face abaxial se mostrava proeminente e pubescente, as intersecundárias eram presentes e abundantes; as nervuras terciárias eram reticulares; a textura era áspera na face abaxial e pouco áspera na face adaxial; a coloração era verde-clara; o pecíolo era cilíndrico, variando de $2,0 \mathrm{~mm}$ a $7,0 \mathrm{~mm}$ de comprimento, com coloração verde, apresentando pubescência densa, tomentosa e dourada.

Nas plantas jovens entre $20,0 \mathrm{~cm}$ a $25,0 \mathrm{~cm}$ de altura os cotilédones estavam ausentes. O caule era cilíndrico, sublenhoso com coloração castanho-claro, piloso por toda extensão igual ao estádio anterior, os catafilos continuavam presentes. As estípulas intrapeciolares descritas anteriormente deixaram cicatrizes quando cairam; o limbo foliar deste estádio se tornou mais uniforme, prevalecendo a forma elíptica com base atenuada e ápice acuminado; a margem era denteada a serreada. Os indumentos, a textura e a coloração eram iguais à fase anterior. 


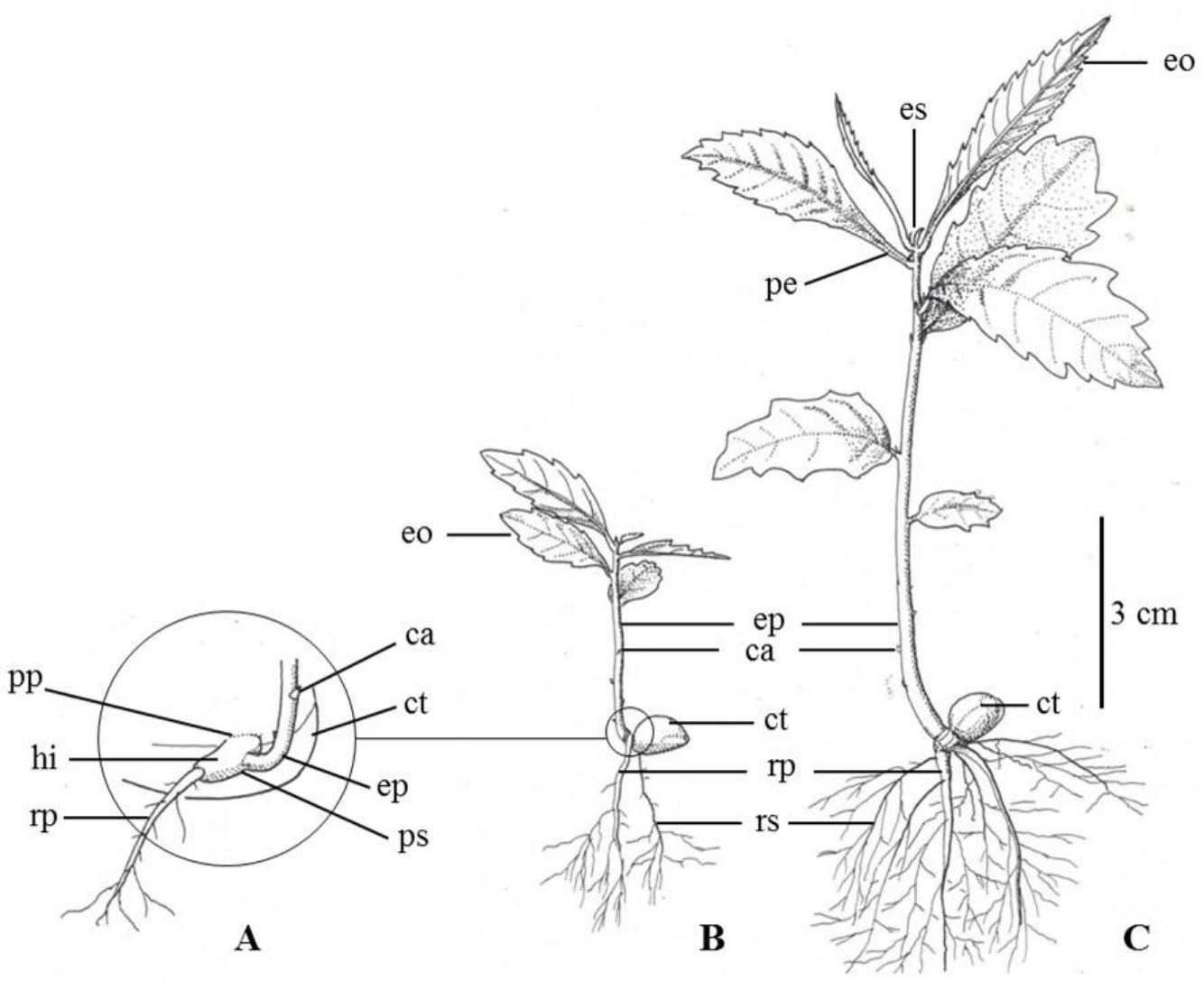

Figura 4. Helicostylis tomentosa Poep. \& Endl. A - Detalhe do hipocótilo e da posição dos cotilédones. B - Plântula normal após 30 dias de germinação em temperatura de ótima $\left(30^{\circ} \mathrm{C}\right)$. C - Planta jovem $(5$ a $10 \mathrm{~cm}$ de altura). ca - catafilo; ct - cotilédones; eo - eofilo; ep - epicótilo; es - estípula terminal; hi hipocótilo intumescido; pe - pecíolo; pp - ponto de inserção do primeiro cotilédone; ps - ponto de inserção do segundo cotilédone; rp - raiz primária; rs - raiz secundária.

As plantas jovens entre $50,0 \mathrm{~cm}$ a $115,0 \mathrm{~cm}$ de altura apresentaram diâmetro médio basal de $0,9 \mathrm{~cm}(0,6 \mathrm{~cm}$ a 1,0 cm). Apresentavam látex discreto ou escasso na região apical, com coloração marrom claro. O caule cilíndrico era glabro na região basal e pubescenteferrugíneo na região apical, a coloração variou de castanho-claro a ferrugíneo. Nessa fase de crescimento os catafilos não eram mais visíveis. Foram observadas lenticelas horizontais por toda extensão do caule, porém mais proeminentes na região basal. Os ramos eram glabros, contudo os ramos jovens apresentaram tricomas do tipo tomentoso com coloração ferrugínea e lenticelas. As estípulas terminais apresentavam tricomas do tipo tomentoso, com forma triangular e ápice atenuado. Com o crescimento de um novo ramo as estípulas terminais tornaram-se intrapeciolares e deixaram cicatriz quando cairam; o pecíolo continuou curto e o indumento anterior piloso se tornou tomentoso. A forma da folha se tornou elíptica a obelíptica com base atenuada a cuneada e ápice acuminado a apiculado nas folhas jovens; a margem era levemente denteada nas folhas jovens e inteiras nas folhas maduras; a venação era pinada quase plana a proeminente, com fácil visualização até as nervuras terciárias; tricomas do tipo tomentoso, foi observado somente nas nervuras primárias e secundárias, e do tipo rígido foi observado nesse estádio em toda superfície da lâmina, tanto na face abaxial como na adaxial das folhas jovens e maduras; o que torna a textura das folhas áspera nas duas faces. As folhas apresentavam a mesma coloração na face adaxial e abaxial (concolor), variando de verde-claro nas folhas jovens a verde-escuro nas folhas maduras. 


\section{Discussão}

\section{Morfometria das infrutescências, frutos e pirênios}

A infrutescência de Helicostylis tomentosa foi descrita de forma semelhante a outras publicações para o gênero e/ou a espécie com a coloração amarela a castanho aveludado e a forma subglobosa a globosa (Berg, 1972; Roosmalen, 1985; Stevenson et al., 2000); o perianto dividido em quatro partes (Berg, 1972; Roosmalen, 1985; Pennington et al., 2004); a formação da infrutescência por um a vários frutos monospérmicos adnatos ao perianto amarelo (Barroso et al., 1999); 1020 pirênios por infrutescência (Stevenson et al., 2000); e os valores médios das dimensões da infrutescência de 2,2 cm x 2,5-5,0 cm (Berg, 1972; Roosmalen, 1985). Informações relacionadas ao aspecto da infrutescência, na dispersão são importantes para o planejamento da coleta e beneficiamento das sementes de $H$. tomentosa .

Barroso et al. (1999) descrevem os frutos da maioria dos gêneros da família Moraceae como nucoides, cobertos por uma polpa carnosa originada do receptáculo e/ou perianto (por exemplo, Dorsteinia, Artocarpus, Chlorophora, Pseudolmedia, Sorocea e Brosimum); porém, o tipo do fruto do gênero Helicostylis não foi mencionado. Souza \& Lorenzi (2005) citam apenas para a família Moraceae que os frutos podem ser drupas ou aquênios, às vezes formando uma infrutescência. As observações desse trabalho estão em concordância com Berg (1972, 1992), que considerou os frutos de Helicostylis também como drupáceos.

Dimensões discrepantes são relatadas na literatura sobre o tamanho dos frutos de H. tomentosa: $0,6-0,7 \mathrm{~cm}$ x 0,5 cm (Berg, 1972, 1992), 6-7 cm de comprimento (Roosmalen, 1985), 2-3 cm de comprimento por 2,9$3,9 \mathrm{~cm}$ de largura (Stevenson et al., 2000) e 2,5-5 cm de diâmetro (Pennington et al., 2004), todavia, estas últimas informações devem-se referir a infrutescência, se for considerado desse modo, as dimensões desse trabalho estão de acordo com Stevenson et al. (2000) e Pennington et al. (2004).

Frequentemente, os pirênios são chamados de sementes na literatura. Corner (1976) já havia mencionado que os pirênios das espécies da família Moraceae são chamados de sementes. Os resultados desse estudo na Amazônia Central apontam pirênios um pouco maiores do que na literatura, que foram de $0,5 \mathrm{~cm} \times 0,4 \mathrm{~cm}$, na descrição de Berg (1972), 0,8 cm x 0,8 cm x 0,5 cm na Guiana, por Roosmalen (1985), e de 0,6-0,8 cm de comprimento na Colômbia, por Stevenson et al. (2000).

A unidade de propagação (diásporo) de Helicostylis tomentosa é um pirênio globoso, marrom opaco, liso e endurecido; a semente é exalbuminosa com embrião axial total e as reservas encontram-se nos cotilédones crassos e isófilos. Relatos sobre os aspectos morfológicos de pirênio, semente e embrião das espécies do gênero Helicostylis não foram encontrados na literatura; sendo essa descrição inédita para o gênero e a espécie estudada.

\section{Descrição do processo germinativo e formação da plântula}

Na tecnologia de sementes, a germinação é avaliada pela formação de plântulas normais, considerando o estádio de desenvolvimento que possui alta probabilidade de estabelecimento em campo. A plântula normal deve apresentar todas as estruturas principais em perfeito estado de desenvolvimento (Brasil, 2009). Dessa forma, o estádio da plântula normal foi considerado quando houve a formação e a expansão dos primeiros eofilos, aos 30 dias após a semeadura (DAS), com a retirada do envoltório. Com 30 DAS as sementes alcançaram $90 \%$ de germinação das sementes germináveis. Desta forma, poder-se-á realizar a primeira contagem do teste de germinação; tempo este oneroso para um teste de germinação em laboratório. Foi observado que a partir de 20 DAS, a plântula apresenta de dois a cinco catafilos, raízes secundárias em abundância e bem distribuídas ao longo do eixo fascicular e as reservas cotiledonares não exauridas. Portanto, esta fase, pode ser utilizada como critério de germinação (plântula normal).

\section{Morfologia da plântula e morfologia comparativa da planta jovem}

Alterações na morfologia externa de $H$. tomentosa foram observadas durante seu desenvolvimento. Os caracteres morfológicos foram similares entre a plântula e a planta jovem até $25,0 \mathrm{~cm}$ de altura, porém muito distinta da morfologia da planta adulta. As diferenças estão basicamente nas folhas, no que se refere a sua forma, margem, indumento e venação; na filotaxia; no caule no que se refere às estruturas e aos indumentos do caule. Essas características podem ser utilizadas para a correta identificação da espécie, mesmo em fase de desenvolvimento inicial.

A transição para a morfologia adulta foi observada em plantas jovens entre $70,0 \mathrm{~cm}$ e $115,0 \mathrm{~cm}$ de altura que 
já apresentam látex. Os caracteres a partir desse estádio permitem identificar a espécie pelas características dos indivíduos adultos descritos por Berg (1972), Ribeiro et al. (1999), Stevenson et al. (2000) e Pennington et al. (2004). Essas características são bons indicativos para a sobrevivência da muda em campo. Adeney et al. (2004) em estudo com espécies de interesse econômico de uma empresa de extração de madeira, no Amazonas, observaram que plantas com látex têm índices de herbivoria significativamente mais baixos que plantas sem látex.

\section{Conclusões}

A coloração amarelada dos frutos e a consistência da infrutescência de $H$. tomentosa são bons indicativos para a extração dos pirênios, facilitando o manejo pós-coleta.

A germinação da semente é do tipo hipógeacriptocotiledonar e, após retirada do endocarpo e sob condições ideais de temperatura, a formação da plântula normal ocorre, em média, aos 30 dias após a semeadura (DAS). Porém, aos 20 DAS a plântula já apresenta as características que podem indicar a formação de uma plântula normal.

As plantas jovens com $5,0 \mathrm{~cm}$ a $25,0 \mathrm{~cm}$ de altura apresentam características morfológicas distintas da planta adulta a respeito da forma, margem, venação e indumento da folha e outras características como a ausência de látex. Somente ao atingir cerca de 1,0 $\mathrm{m}$ de altura a planta juvenil inicia a aquisição das características morfológicas do indivíduo adulto, sendo essa fase a ideal para o plantio.

\section{Agradecimentos}

A Mutsuko Nakajima, pelas ilustrações botânicas. A Lílian Procópio, pela ajuda na descrição das plantas jovens. A Augusto Santos, pela digitalização das imagens. A Warley Arruda, pela paciente ajuda na montagem final das imagens. Ao programa JICA e aos institutos CAPES, CNPq e FAPEAM pela possibilidade de execução da pesquisa.

\section{Referências}

Adeney, J. M. et al. El látex como defensa anti-herbívoros em la zona de extraccíon sustentable de Madereira Mil, Amazonia brasileña. In: Camargo \& Machado (Ed.). Livro do curso de campo "Ecologia da Floresta Amazônica”. Manaus: PDBFF/INPA, 2004. Disponível em: <http://pdbff.inpa.gov.br/cursos/efa/livro/2004/PDFs/pl1g2. pdf $>$. Acesso em: 13 dez. 2017.

Barroso, G. M. et al. Frutos e sementes: morfologia aplicada à sistemática de dicotiledôneas. Vicosa, MG: Ed. da UFV, 1999. 443 p.

Berg, C. C. Moreae, Artocarpeae, and Dorstenia (Moraceae) with introductions to the family and ficus and with additions and corrections to Flora Neotropica Monograph 7. New York: New York Botanical Garden, 2001.346 p. (Flora neotropica. Monograph, $83)$.

Berg, C. C. Moraceae. In: Görts-Van Rijn, A. R. A. (Ed). Flora of the Guianas. Koenigstein: Koeltz Scientific Books, 1992. p. 10-92. (Series A. Phanerogams, 11).

Berg, C. C. Olmedieae, Brosimeae (Moraceae). New York: Hafner, 1972. 228 p. (Flora neotropica. Monograph, 7).

Brasil. Ministério da Agricultura, Pecuária e Abastecimento. Secretaria de Defesa Agropecuária. Regras para análise de sementes. Brasília, DF, 2009. 395 p.

Camargo, J. L. C. et al. Guia de propágulos e plântulas da Amazônia. Manaus: Inpa, 2008. v. 1. 168 p.

Corner, E. J. H. The seeds of dicotyledons. Cambridge: Cambridge University Press, 1976. v. 1.311 p.

Ferraz, I. D. K. et al. Efeito da temperatura na germinação de sementes florestais da Amazônia. In: Higuchi, N. et al. (Ed.). Pesquisas florestais para a conservação da floresta e reabilitação de áreas degradadas da Amazônia. Manaus: Inpa: JICA, 1998. p. 185-199.

Flora do Brasil 2020 em construção. Helicostylis. Rio de Janeiro: Jardim Botânico do Rio de Janeiro, [2016]. Disponível em: $<$ http:// floradobrasil.jbrj.gov.br/reflora/floradobrasil/FB10183>. Acesso em: 7 ago. 2016.

Font-Quer, P. Diccionario de botánica. 2 ed. Barcelona: Península, 2001. $1244 \mathrm{p}$.

Gogosz, A. M. et al. Morfoanatomia da plântula de Campomanesia xanthocarpa O. Berg. (Myrtaceae). Acta Botanica Brasilica, v. 24, n. 3, p. 613-623, 2010.

Hickey, M. \& King, C. The Cambridge illustrated glossary of botanical terms. Cambridge: Cambridge University Press, 2000. $208 \mathrm{p}$.

Hong, T. D. et al. Compendium of information on seed storage behaviour. London: Royal Botanical Garden Kew, 1998. 2 v. 901 p.

Martin, A. C. The comparative internal morphology of seeds. The American Midland Naturalist, v. 36, n. 3, p. 513-660, 1946.

Mensbruge, G. de L. A. Étude morphologique dês plantules des principales essences forestières. In: Mensbruge, G. (Ed.). La germination et lês plantules des essences arborées de la forêt dense humide de la côte d'ivoire. Nogent-sur-Marne: CTFT, 1966. p. 97-342. (Publication du Centre technique forestier tropical, 26).

Paoli, A. A. S. \& Bianconi, A. Caracterização morfológica de frutos, sementes e plântulas de Pseudima frutescens (Aubl.) Radlk. (Sapindaceae). Revista Brasileira de Sementes, v. 30, n. 2, p. 146- 
$155,2008$.

Pennington, T. D. et al. Illustrated guide to the trees of Peru. Sherborne: D. Hunt, 2004. 848 p.

Ribeiro, J. E. L. da S. et al. Flora da reserva Ducke: guia de identificação das plantas vasculares de uma floresta de terra-firme na Amazônia Central. Manaus: INPA, 1999. 799 p.

Roosmalen, M. G. M. van. Fruits of the Guianan flora. Utrecht: Institute of Systematic Botany, 1985. 483 p.

Roth, I. Fruits of angiosperms. In: Linsbauer, K. (Ed.). Encyclopedia of Plant Anatomy, v. 10, n. 1, p. 33-101, 1977.

Souza, V. C. \& Lorenzi, H. Botânica sistemática: guia ilustrado para identificação das famílias de Angiospermas da flora brasileira, baseado em APG II. Nova Odessa: Instituto Plantarum, 2005. 640 p.

Steege, H. T. et al. Ecology and logging in a tropical rain forest in Guyana. Wageningen: The Tropenbos Foundation, 1996. 123 p. (Tropenbos. Series, 14).

Steege, H. T. et al. Hyperdominance in the Amazonian tree flora. Science, v. 342, p. 325, 2013.

Stevenson, P. R. Guía de frutos de los Bosques del Río Duda La Macarena, Colombia. Macarena: Asociación para la Defensa de la Reserva de La Macarena; Netherlands Committee for IUCN; Tropical Rain Forest Programme, 2000. 467 p. 
